\title{
iPS and ES Cells: Do Both Roads Lead to Rome?
}

\author{
Valerie Y. Ng and Andre B.H. Choo*
}

Stem Cell Group, Bioprocessing Technology Institute, 20 Biopolis Way \#06-01 Centros 138668, Singapore

\begin{abstract}
The seminal report from Takahashi and Yamanka in 2006 describing the reprogramming of somatic cells to induced pluripotent stem (iPS) cells [1] marked the beginning of a new field of research, resulting in hundreds of publications in a short 3 years. Among other things, the promise of iPS cells in cell therapy circumvents many of the ethical concerns associated with embryonic stem (ES) cell research, and autologous patient-specific cells can be generated. Nonetheless, the jury is still out on the extent to which iPS cells and ES cells are functionally equivalent. This review focuses on the genetic and functional comparisons between these two cells types.
\end{abstract}

Keywords: Embryonic stem cells, induced pluripotent stem cells, antibodies, differentiation, insulin, cardiomyocyte, motor neurons, dopaminergic neurons, hepatocytes, hematopoeitic cells, retinal pigmented epithelium cells.

\section{CHARACTERIZATION OF iPS CELLS}

One of the challenges of iPS cell research is to carefully establish standards and minimum criteria for the identification and characterization of iPS cells. As the strategies for generating iPS cells evolve from the introduction of transcription factors via viral vector methods through to small molecules, and optimal sources of cells for reprogramming are identified, a consensus set of assays has to be agreed upon for relevant and meaningful comparative data to be generated. Otherwise, the consequence could be ambiguity arising from a myriad of irrelevant and disparate results generated from unstandardized cell lines and methods of characterization.

The criteria used to characterize iPS cells are very similar to that employed for ES cell research. For example, the seminal and subsequent papers reporting the generation of human iPS cells $[2,3]$, describe them as exhibiting many of the hallmark indicators of human ES cells [4, 5] (Table 1). Despite the similarities there are, however, differences between iPS cells and their ES cell counterparts.

Typically, assessment of gross morphology is used for initial isolation of iPS cells. Colonies of compact cells exhibiting a high nucleus to cytoplasmic ratio resembling human ES cell cultures will appear 3-4 weeks after reprogramming. In addition, iPS cells and ES cells have comparable growth rates and doubling times [2, 3], and express cell surface markers such as stage-specific embryonic antigen (SSEA)-3, SSEA-4, Tra-1-60, Tra-1-81; transcription factors OCT3/4 and NANOG. Moreover, iPS cells typically have elevated telomerase and alkaline phosphatase activities (Table 1). These phenotypes have been observed for iPS cells generated from healthy donors and patients with a variety of genetic diseases. The latter includes disorders with either Mendelian or complex inheritance such

*Address correspondence to this author at the Stem Cell Group, Bioprocessing Technology Institute, 20 Biopolis Way \#06-01 Centros 138668, Singapore; Tel: (65) 6478 8888; Fax: (65) 6478 9561; E-mail: andre_choo@bti.a-star.edu.sg as adenosine deaminase deficiency-related severe combined immunodeficiency (ADA-SCID), Shwachman-Bodian-Diamond syndrome (SBDS) and Gaucher disease (GD) type III [6].

Our group has raised and characterized a panel of monoclonal antibodies (mAbs) specific to cell surface markers on human ES cells [7]. We have recently compared the reactivity of our panel of mAbs to iPS cell lines (ES4SKIN and ESIMR90) [2], 21 day embryoid bodies (EB) derived from iPS cells, their respective parental fibroblast lines and undifferentiated human ES cells, and found that reactivity of all the mAbs towards iPS and human ES cells was similar (unpublished data). Furthermore, all but 2 of the antibodies had no reactivity to 21 day EB or the parental fibroblast lines. Uniquely, one of the clones from our panel of $\mathrm{mAb}, \mathrm{mAb} 84$, not only binds to podocalyxin (PODXL) on human ES cells, it also selectively kills undifferentiated human ES cells via pore formation, resulting in membrane damage and leading to oncotic cell death [8]. When tested on iPS cells, the efficiency of cell killing by mAb 84 was comparable for iPS cells and human ES cells (>90-95\%) while absent for EB and the fibroblast lines (unpublished data).

At the genetic level, one crucial difference between iPS cells and human ES cells is the introduction/integration and expression of genes essential for the reprogramming process. ES cells are directly derived from the inner cell mass of the blastocyst and do not require additional perturbation of the genome. iPS cells by-and-large continue to maintain a normal karyotype (46 chromosomes) after prolonged culture (e.g. $>7$ months) [9]. It should however be noted that like human ES cells, continuous passaging of iPS cells as a single cell culture (e.g. $\sim 13$ passages [9]) can result in karyotype changes especially involving chromosomes 17 and 20. Thus, monitoring karyotype stability is necessary for extended culture of both iPS cells and human ES cells.

Clonality may be another important criterion for establishing iPS cell lines. After reprogramming, iPS cells generated under identical conditions are by no means 
Table 1. Characterization of iPS Cells and Human ES Cell

\begin{tabular}{|c|c|c|c|c|c|c|c|c|c|}
\hline & \multicolumn{9}{|c|}{ Cell Types } \\
\hline & $\begin{array}{c}\mathrm{Yu}, \\
2007[2]\end{array}$ & $\begin{array}{l}\text { Takahashi, } \\
2007[3]\end{array}$ & $\begin{array}{c}\text { Park, } \\
2008[6]\end{array}$ & $\begin{array}{c}\text { Park, } \\
2008[17]\end{array}$ & $\begin{array}{l}\text { Aasen, } \\
2008 \text { [9] }\end{array}$ & $\begin{array}{l}\text { Huangfu, } \\
2008 \text { [13] }\end{array}$ & $\begin{array}{l}\text { Thomson, } \\
1998 \text { [5] }\end{array}$ & $\begin{array}{l}\text { Reubinoff, } \\
2000[4]\end{array}$ & $\begin{array}{l}\text { Heins, } \\
2006[75]\end{array}$ \\
\hline $\begin{array}{c}\text { Morphology } \\
\text { High nucleus to cytoplasmic } \\
\text { ratio }\end{array}$ & $\checkmark$ & $\checkmark$ & $\checkmark$ & $\checkmark$ & $\checkmark$ & $\checkmark$ & $\checkmark$ & $\checkmark$ & $\checkmark$ \\
\hline $\begin{array}{c}\text { Immunocytochemistry/FACS } \\
\text { Surface markers } \\
\text { SSEA-3 } \\
\text { SSEA-4 } \\
\text { Tra-1-60 } \\
\text { Tra-1-81 } \\
\text { Transcription Factors } \\
\text { Oct4 } \\
\text { Nanog }\end{array}$ & $\begin{array}{l}\checkmark \\
\checkmark \\
\checkmark \\
\checkmark \\
- \\
-\end{array}$ & $\begin{array}{l}\checkmark \\
\checkmark \\
\checkmark \\
\checkmark \\
- \\
\checkmark\end{array}$ & $\begin{array}{l}\checkmark \\
\checkmark \\
\checkmark \\
\checkmark \\
\checkmark \\
\checkmark\end{array}$ & $\begin{array}{l}\checkmark \\
\checkmark \\
\checkmark \\
\checkmark \\
\checkmark \\
\checkmark\end{array}$ & $\begin{array}{l}\checkmark \\
\checkmark \\
\checkmark \\
\checkmark \\
\checkmark \\
\checkmark\end{array}$ & $\begin{array}{l}- \\
\checkmark \\
\checkmark \\
\checkmark \\
\checkmark \\
\checkmark\end{array}$ & $\begin{array}{l}\checkmark \\
\checkmark \\
\checkmark \\
\checkmark \\
- \\
-\end{array}$ & $\begin{array}{l}- \\
\checkmark \\
\checkmark \\
- \\
- \\
-\end{array}$ & $\begin{array}{l}\checkmark \\
\checkmark \\
\checkmark \\
\checkmark \\
\checkmark \\
-\end{array}$ \\
\hline $\begin{array}{l}\text { Alkaline Phosphatase } \\
\text { activity }\end{array}$ & $\checkmark$ & $\checkmark$ & $\checkmark$ & $\checkmark$ & $\checkmark$ & $\checkmark$ & $\checkmark$ & $\checkmark$ & $\checkmark$ \\
\hline Telomerase activity & $\checkmark$ & $\checkmark$ & - & - & - & - & $\checkmark$ & & $\checkmark$ \\
\hline Microarray/qRT-PCR & $\checkmark$ & $\checkmark$ & - & $\checkmark$ & $\checkmark$ & $\checkmark$ & - & $\checkmark$ & - \\
\hline Embryoid body formation & $\checkmark$ & $\checkmark$ & $\checkmark$ & $\checkmark$ & $\checkmark$ & $\checkmark$ & - & - & $\checkmark$ \\
\hline Teratoma formation & $\checkmark$ & $\checkmark$ & $\checkmark$ & $\checkmark$ & $\checkmark$ & $\checkmark$ & $\checkmark$ & $\checkmark$ & $\checkmark$ \\
\hline Normal karyotype & $\checkmark$ & $\checkmark$ & $\checkmark$ & $\checkmark$ & $\checkmark / x$ & $\checkmark$ & $\checkmark$ & $\checkmark$ & $\checkmark$ \\
\hline
\end{tabular}

homogeneous. Cells are at different stages of reprogramming and risk integration and insertional mutagenesis, which render them refractory to differentiation with increased potential to form immature teratomas [10]. Masaki and colleagues observed that even alkaline phosphatase (ALP)positive colonies can be categorized into 40 groups based on the gene expression pattern of 8 marker genes - Nanog, TDGF1, Dnmt3b, Zfp42, FoxD3, GDF3, CYP26A1 and Tert [11]. Screening resulted in the isolation of 3 iPS cell lines that were positive for all 8 marker genes (only 4 out of 162 ALP+ clones expressed the 8 marker genes $\sim 0.02 \%$ ). Importantly, these findings support the need to definitively isolate and characterize bona fide iPS cells while removing aberrantly reprogrammed cell populations. Unfortunately, clonal selection has to be performed against the background of poor survival of stem cells when passaged as single cells. To this end, Rho-associated kinase (ROCK) inhibitor could be used, with single cell survival previously shown to improve by approximately 8-9 fold at day 7 post-seeding [12].

Other comparisons between iPS and human ES cells include analysis of the methylation status for promoters of ES-cell specific genes, telomerase activity, gene-specific quantitative or semi-quantitative RT-PCR and genome-wide gene expression profiling. Methylation status of cytosine guanine dinucleotides $(\mathrm{CpG})$ in the promoter regions of pluripotent genes such as OCT4, NANOG and REX1 on iPS cells, the parental fibroblasts and human ES cells were compared using bisulfite genomic sequencing [3, 13]. Consistently, the promoter regions of these genes were predominantly unmethylated in iPS cells and human ES cells while they was highly methylated in the parental fibroblast lines [3, 13]. Another similarity between iPS cells and human ES cells is high telomerase activity. Interestingly, Marion and colleagues observed that after reprogramming, telomere elongation occurred as a consequence of increased telomerase activity [14]. At early passages, the telomere length is intermediate between the parental fibroblast and ES cells. At later passages, the telomere length is comparable between iPS cells and ES cells. In addition, the conformation of the telomere heterochromatin and a reduced density of histone heterochromatin marks (H3K9m3 and H4K20m3) were similar between the 2 cell types [14]. Similarly, using ChIP-chip technique, Maherali and colleagues found that promoter regions of $>900$ ESC signature genes in iPS cells were reset to the same epigenetic state (bivalent domains) as their ES cell counterparts [15].

The expression of ES cell specific genes such as OCT-4, NANOG, REX-1, KLF1, hTERT, GDF-3 has been analyzed using qRT-PCR. The expression of these genes is elevated in iPS cells compared to the parental fibroblast cells, and comparable to human ES cells $[16,17]$. Several groups have utilized DNA microarrays to compare the global gene expression profile of iPS cells, the non-reprogrammed fibroblasts, and ES cells. Based on the gene set defined by the International Stem Cell Initiative [18], Masaki and colleagues found that 3 human iPS cell lines generated by them clustered with a panel of human ES cell lines but were separated from their parental fibroblast cells [11]. Similar results were also observed in separate studies by $\mathrm{Yu}$ and 
Takahashi where iPS cells and human ES cell gene expression profiles were by-and-large similar [2, 3]. It is however interesting to note that there are variations between human ES and iPS cells; and also within different clones of iPS cells. Out of the 32266 transcripts compared by Takahashi et al., 4\% (1267 genes) were either up-or downregulated by $>5$-fold between iPS cells and ES cells [3]. Similarly, Chin et al. observed that there was a distinct gene expression signature between early and late passages of human iPS cells [19]. Early passage iPS cells clustered more closely with the parental fibroblast whilst late passage iPS cells resembled hESC. The authors suggested that at early passages, iPS cells are probably incompletely reprogrammed - either due to inefficient silencing of fibroblast-specific genes or incomplete induction of hESC-specific genes. However, when the cultures are extended, the majority of the differences between human ES cells and iPS cells are resolved [19]. This phenomenon is unique to iPS cells despite the route of reprogramming and this variability was not observed between early and late passages of human ESC.

Studies of in vitro and in vivo differentiation are useful for testing stem cell pluripotency. iPS cells have been differentiated in vitro, either spontaneously to embryoid bodies followed by real-time PCR analysis for expression of genes from the 3 germ layers or directed towards specific lineages [20]. Unlike mouse iPS cells where pluripotency can be demonstrated beyond doubt through the generation of germline chimeras, the equivalent experiment cannot be performed for human iPS cells. The best alternative is to test teratoma formation in SCID mice. Like human ES cells, iPS cells can form teratomas in vivo after reprogramming [2, 3]. However, it should be noted that teratoma formation does not guarantee pluripotency as there are instances of mouse ES-like cells that form teratomas but do not produce germline chimeras [10]. Ellis and colleagues suggest that perhaps a non-teratoma forming iPS cell line may be a "desirable" outcome as this removes the risk of residual in vivo tumorgenicity after transplantation of cells [21]. Nonetheless, iPS cells must retain the capacity to efficiently generate a desired cell/tissue type and hence a greater understanding of their behavior is necessary.

\section{FUNCTIONAL APPLICATIONS OF iPS CELLS}

A salient question about iPS cells is whether they can be differentiated into clinically relevant cell types. Given the similarity between human ES and iPS cells, the large body of work on lineage-specific differentiation of ES cells is informative for iPS cell differentiation (Table 2). Once determined, differentiated cells could theoretically be considered for autologous cell transplantation and tissue engineering, with information to be gleaned about in vivo development, disease progression and drug screening from in vitro modeling [22].

\section{Neuronal Cells}

Neurodegenerative diseases such as Parkinson's disease result from the deterioration of neurons in the brain and spinal cord. The ability for endogenous neurons to regenerate is limited, with a loss of or damage to neurons having a devastating effect on the individual. Clearly the derivation of functional and clinically-compliant neuronal cell types in vitro will be of great therapeutic benefit. Methods for differentiating human ES cells into neural precursors (NPs) is an area of intense research [23, 24], more recently extending to iPS cell differentiation. Comparative studies of ES and iPS neuronal derivatives are important to determine the latter's regenerative potential and ultimately their use for modeling neurodevelopment and neurological disorders $[25,26]$ and as patient-specific immuno-compatible cells for transplantation therapy.

Motor neurons are required for the control of essential voluntary movements including breathing, swallowing, speaking, walking, and overall body movements. Degeneration of motor neurons results in diseases such as primary lateral sclerosis, amyotrophic lateral sclerosis (also known as Lou Gehring's disease), and spinal muscular atrophy. Several groups using a variety of cell clones and lineage specific protocols have achieved the derivation of electrophysiologically active motor neurons from iPS cells [27-29]. Although the differentiation of neuronal subtypes from iPS and human ES cells appear to follow developmental cues in a similar fashion, the overall differentiation efficiency of some, but not all, iPS clones remain lower than that in human ES cells. These differences could be attributed to the clonal variations across cell lines [29].

The production of disease-relevant cell types from patient-specific stem cells will enable researchers to better study the etiology and progression of the disease in vitro, and successfully derive cells for autologous transplantation. To this end, human iPS cells from patients suffering from motor neuron diseases amyotrophic lateral sclerosis (ALS) and spinal muscular atrophy (SMA) have been generated $[30,31]$. The iPS cells were then further differentiated to the relevant neuronal cell types, which importantly, still maintained the cognate mutations in the disease-causing gene. Since disease progression can be recapitulated in these patient-derived cells, these iPS cells can aid in the study of factors that contribute to the disease. In addition, diseasespecific human iPS cells will be useful in drug screens for potential xenobio-tic candidates. Indeed, the SMA-iPS cells demonstrated the expected increase in survivin motor neuron 1 after treatment with valproic acid and tobramycin [31]. In a separate study, neural crest precursos from familial dysautonomia iPS clones were used to screen candidate drugs that can reverse the effects of the disease-causing I $\mathrm{I} B$ kinase complex-associated protein and one candidate, kinetin, resulted in partial restoration of the disease phenotype [32].

The generation of dopamine neurons from a human iPS line and from skin biopsies of Parkinson's patients have also been reported $[33,34]$. Importantly, the authors were able to achieve viral-free reprogramming of the skin fibroblasts via Cre-recombinase excisable vectors, thus eliminating the risk of re-expression of the reprogramming factors [33]. Both dopaminergic neurons of mouse and human iPS origins can also be successfully transplanted into the 6-OHDA lesioned Parkinson's rats and result in long term survival and functional rescue of the disease phenotype [34, 35]. However the authors cautioned that cell therapy may not represent an end-all solution as the cause of neural degeneration in 
Table 2. Differentiated Cell Types Derived from Mouse iPS and Human iPS Cells

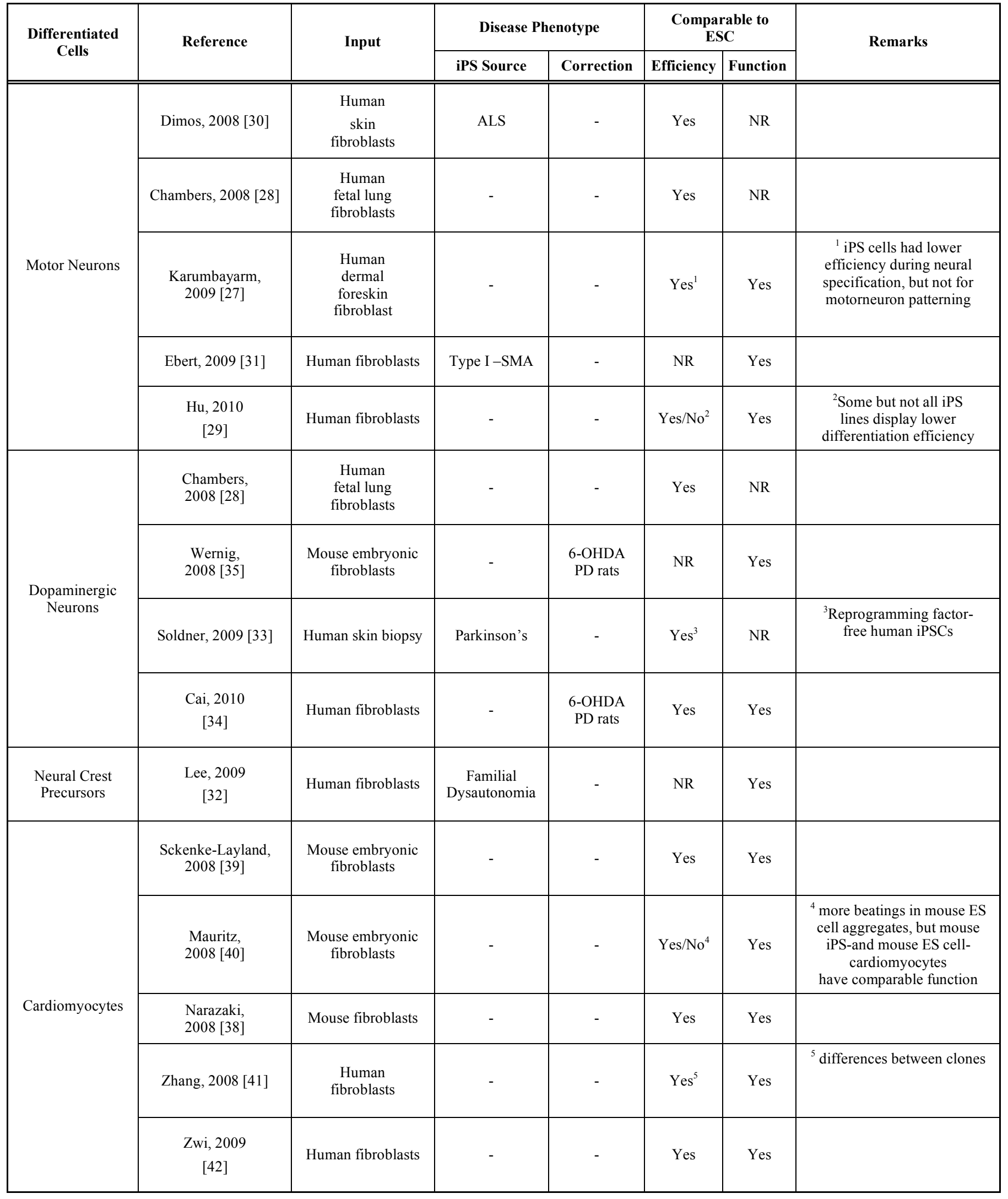


(Table 2) Contd.....

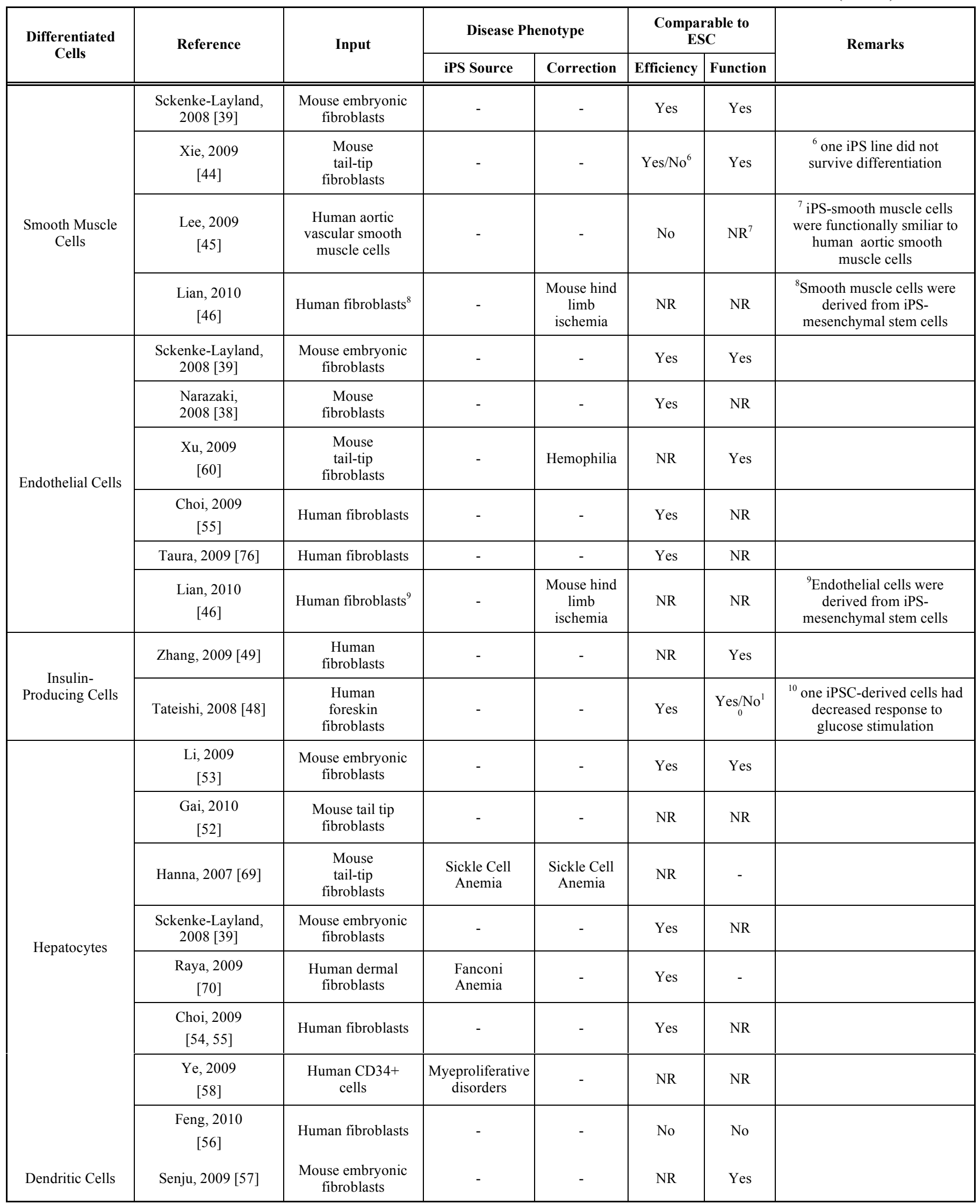


(Table 2) Contd.....

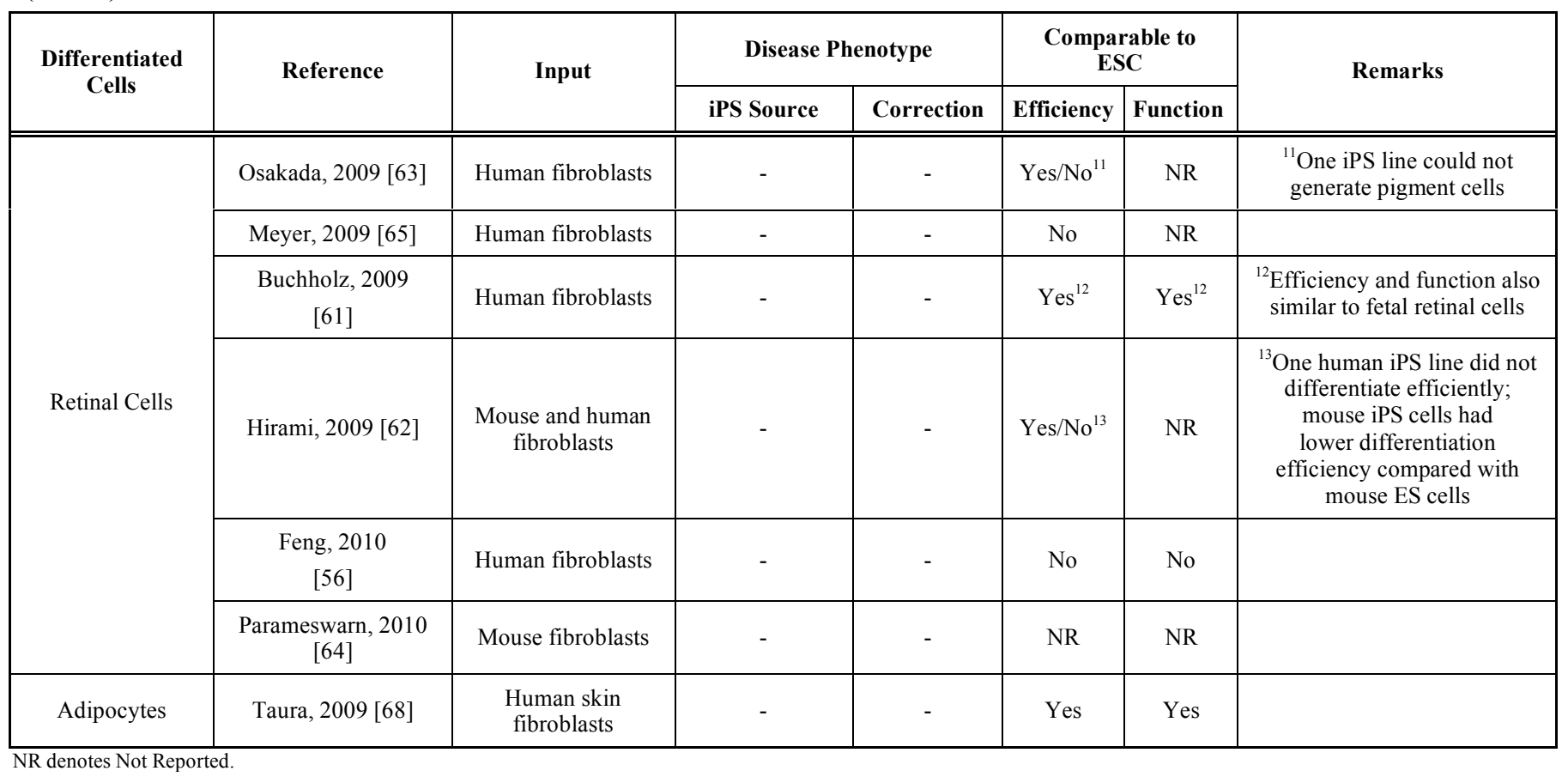

Parkinson's is still unknown, thus the transplanted cells may still be subject to the same genetic and/or disease-causing factors.

\section{Cardiovascular Cell Types}

Myocardial infarction is an ischemic event where blood perfusion through the heart is unable to keep up with the demand, eventually leading to the loss of cardiomyocytes [36]. As mature cardiomyocytes are terminally differentiated cells, they have liminted regenerative potential, thus there is a need to repair cardiomyocytes or supply them from an external source [37]. iPS cells are an attractive souce of cardiomyocytes since autologous derivation of syngeneic cardiomyocytes ensures compatibility with the host immune system. The ability of iPS-cardiomyocytes to incorporate into the heart and become integrated into the natural electrical impulses is among other challenges that need to be addressed before ES-derived cardiomycocytes can reach the clinic.

Several groups have reported the successful differentiation of functional cardiomyocytes from mouse ES cells and iPS cells. Using the early endothelial marker Flk-1 to enrich for cardiac cells followed by a systematic differentiation protocol, cardiomyocytes, arterial, venous, smooth muscle, and lymphatic endothelial cells have been generated $[38,39]$. Cardiac cells could also be differentiated by forming mouse iPS cell aggregates However, mouse ES cells-derived aggregates exhibited a larger percentage of contracting areas when compared to mouse iPS aggregates, whose peak percentage of contracting areas was also delayed [37]. In general, efficiency and lineage marker expression of mouse iPS cell- and ES cell cardiac derivatives were not statistically different regardless of the differentiation method. More importantly, extensive physiological characterizations of mouse iPS cell- and ES cell-cardiomyocytes showed that they were phenotypically indistinguishable in terms of beating rates and the ability to generate $\mathrm{Ca}^{2+}$ transients and membrane potentials. Furthermore, the mouse iPS and ES cell-smooth muscle cells displayed similar contraction patterns after carbachol treatment and comparable uptake of acetylated low-density lipoprotein [38-40]. Interestingly, Mauritz et al. reported that the level of pluripotent markers NANOG and OCT3/4 were downregulated more slowly in mouse iPS cells during differentiation, which possibly contributed to the later appearance of the mesodermlike phenotype in these cells [40].

Cardiomycytes derived from human ES and iPS cells have been shown to be similar and also functionally variable within clones of each cell type [41, 42]. Even within the same study where two ES cell and two iPS cell lines were compared side-by-side, one ES cell line displayed higher beating percentage over the other ES cell and iPS cell lines. However, all lines expressed similar levels of cardiacspecific genes, comparable percentage of nodal, atrial, and ventricular-like action potentials, action potential durations, amplitudes, diastolic potentials, and functional B-adrenergic signaling [41, 42]. Therefore, cardiomyocytes derived from either human ES or iPS cells may be functionally similar, and variations could be attributed to the intrinsic heterogeneity between cell lines. As reported in mouse iPS cells, pluripotency markers OCT4 and NANOG were not down regulated in iPS cells as rapidly as in ES cells, possibly due to the persistent expression of these transgenes during differentiation [41].

Smooth muscle cells are involved in the maintenance of vascular tone, thus the balance of a heterogeneous population of smooth muscle cells is important for the control of blood pressure and distribution of blood flow [43]. Part of the pathogenesis of cardiovascular diseases involves the dysregulation of differentiation and dedifferentiation of smooth muscle cells, and models to study this process in vitro are lacking. Smooth muscle cells have been obtained 
from both mouse and human iPS sources. In the report by Xie et al. the authors compared smooth muscle cells derived from two mouse iPS cell lines and two mouse ES cell lines [44]. One mouse iPS cell line did not survive the differentiation, but the remaining iPS and ES cell lines differentiated with equal efficiency and were determined to be functionally responsive to carbachol and caffeine treatment. In a slightly different approach, Lee and colleagues reprogrammed human aortic smooth muscle cells to iPS cells, then re-differentiated them to smooth muscle cells [45]. Both of the human iPS-smooth muscle cells and human ES-smooth muscle cells highly expressed the smooth muscle markers $\alpha$ and $\gamma$-smooth muscle actin. A functional demonstration of iPS-derived vascular cells was carried out where human iPS-derived mesenchymal stem cells induced vascular and muscle regeneration, leading to the attenuation of limb ischemia in mice [46]. In fact, iPS-mesenchymal stem cells stained significantly higher for smooth muscle and endothelial cells, and had prolonged engraftment survival as compared to bone marrow-derived mesenchymal stem cells, further demonstrating the in vivo utility of iPS-derived cells in tissue repair [46].

\section{Insulin-Secreting Cells}

One treatment for diabetes is to transplant insulinsecreting pancreatic ß-cells into patients [47]. However, since the supply of donor pancreas is often limiting, there is a need for other means of generating insulin-secreting cells. There is much ongoing research in the derivation of pancreatic B-cells from ES cells, with a few recent studies focusing on iPS cells. Stepwise differentiation protocols have been used to generate insulin-secreting cells [48, 49]. In the study by Teteishi et al., two human iPS cell clones and one human ES cell line were subject to differentiation and both showed similar gene and protein expression of appropriate stage-specific markers. C-peptide and glucagon were also detectable in cells derived from human iPS cells and human ES cells; however when stimulated with high glucose, one human iPS clone responded poorly with regards to insulin secretion, while the other human iPS clone secreted a comparable amount of insulin as the human ES cellderived clone [48]. It is also important to note that although human ES cell- and human iPS cell-derived pancreatic cells are capable of insulin secretion upon glucose stimulation, they still are unable to achieve levels comparable to that of adult human $\beta$-cells, thus more efficient differentiation protocols still need to be established.

\section{Hepatocytes}

Patients suffering from end stage-liver disease have to await transplantation as the adult liver is unable to replace the loss in liver mass by regnerating sufficient hepatocytes. Primary hepatocytes are a potential source for transplantation but the demand for them greatly exceeds the supply. In addition, primary hepatocytes have limited proliferative potential and sufficient amounts are difficult to generate. Therefore, the use of stem cells as a source of hepatocytes is a promising option [50,51]. Murine hepatocytes expressing mature hepatic markers such as albumin and alphafetoprotein have been derived from mouse iPS and ES cells with comparable efficiency [52, 53]. In addition, these mouse iPS-hepatocytes exhibit relevant functional characteristics of liver cells including cytoplasmic glycogen storage, LDL uptake, and urea production. Moreover, the iPS-derived liver cells could be successfully grafted into mouse recipient livers [52].

\section{Hematopoietic Cells}

Multipotent hematopoietic stem cells can give rise to cells of the myeloid and lymphoid lineages that play important roles in the immune system. The ability to study human variants of these cells has been limited by the availability of bone marrow cells, from which the hematopoietic stem cells originate. The induction of mature hematopoietic cells from mouse and human iPS cells bearing similar marker expression and morphology as those derived from their ES counterparts has been achieved by separate groups. However, these studies differ in their assessment of the functional characteristics of the resulting differentiated cells [54-57]. In particular, the study by Feng and colleagues saw a significant reduction in the survival and expansion of the hemangioblast (a bipotent progenitor population), endothelial, and retinal pigmented epithelium cell population when compared with human ES cell-derivatives [56]. The differrences in differentiation potential of iPS and ES cells highlight the need for more stringent evaluation criteria for iPS cells.

Patient-specific hematopoeitic cells have also been derived from reprogrammed peripheral blood CD34+ cells that present with myeloproliferative disorders [58]. The iPShematopoietic progenitors recapitulated the disease phenoltype of increased erythropoiesis and offer the potential to further investigate myeloproliferative disorder pathogenesis.

Hemophilia $\mathrm{A}$ is a monogenic coagulation disorder caused by deficiencies of FactorVIII and is also a candidate target for gene therapy [59]. Although gene therapy approaches have been used to correct the defect, it has been met with limited success mainly due to the response from host immune cells and the insufficient production of a sustained amount of the gene product. By injecting mouse iPS cells that were differentiated to progenitor and mature endothelial cells into an irradiated mouse model of hemophilia, $\mathrm{Xu}$ et al. demonstrated a correction of the disease phenotype [60]. The mature endothelial cells expressed characteristic markers of the endothelial lineage and importantly, also expressed Factor VIII. When the injected mice were challenged to a tail-clip bleeding assay, these mice survived for more than 3 months, as compared to the non-injected counterparts, which survived for a few hours. Analysis of the pathological features such as hemoglobin levels, reticulocyte count and morphology, and urine concentration defect showed improvement in the gene-corrected iPS cell-injected mice [60]. The question remains whether the transplanted cells are able to effect long-term correction of the hemophilia phenotype.

\section{Retinal Pigmented Epithelium Cells}

In retinal degenerative diseases, vision can be severely impaired by damage to retinal photoreceptors (RPE). The ability to generate immune-compatible RPE cells from autologous iPS cells represents a solution to replace the 
diseased cells. To that end, several groups have successfully generated retinal cells including retinal progenitors, retinal pigmented epithelium, retinal ganglion cells, cone, and rod photoreceptors from mouse and human iPS cells [56, 61-65]. A comparison between human iPS cells reprogrammed using three- or four-factors did not yield considerable differences in differentiation efficiency and function [63], neither did reprogramming using "Yamanaka" or "Thomson factors" [61-64]. However, considerable variability was found amongst iPS cell lines in their ability to generate $\mathrm{Pax}^{+}$cells, a marker for early precursors of retinal pigmented epithelium [65]. In most cases, apart from the expression of cell-type appropriate markers, further characterization of the iPSretinal cells is still required to determine the functional utility of these cells in rescuing a diseased phenotype.

\section{Adipocytes}

Lipodystrophy is a medical condition characterized by the loss of adipose tissue and is linked to conditions such as insulin-resistance, hepatomegaly, and hypermetabolism [66]. The etiology of this disease is not well understood, and significant differences exist between adipocyte development in mice and humans [67]. Human iPS-adipocytes could therefore serve as a model to study the progression of lipodystrophy. Generation of adipocytes from 4 human iPS cell clones was reported and compared with the differentatiation potential of 2 separate human ES cell lines [68]. Human iPSand ES cell-adipocytes were similar in terms of marker expression and lipid accumulation potential, although variations existed within each cell type [68].

\section{iPS Cells in Gene Therapy}

One of the difficulties in bringing gene therapy into the clinic is the risk of immune rejection. With autologous iPS cells, this problem can at least be circumvented. Studies have demonstrated the possibility of correcting or complementtating a mutated gene in using iPS cell-based methods.

Ideal targets for gene therapy are single-gene disorders such as sickle cell anemia, where the repair of one gene can correct the disease phenotype. In that respect, Hanna and colleagues were able to show that wild-type iPS-hematopoeitic progenitor cells can be derived from the diseased mouse by replacing the diseased $\beta$-globin genes by the healthy allele [69]. When the normal iPS-hematopoetic progenitor cells were injected into irradiated sickle mice, the treated mice showed improvement in all pathological features of sickle cell anemia, with decreased anisocytosis and normal red cell counts among other parameters, thereby demonstrating that disease-corrected iPS cells can indeed be used in vivo to treat a disease phenotype [69].

Fanconi Anemia (FA) is caused by chromosomal instability of any of the genes in the FA pathway, resulting in decreased numbers of hematopoietic cells. Using dermal fibroblasts of FA patients, Raya et al. corrected the FA phenotype by genetic complementation followed by reprogramming into iPS cells [70]. Interestingly, only FAcorrected cells could to be reprogrammed into human iPS cells, showing that FA restoration is indispensable for reprogramming to occur [70]. Unlike studies where mouse iPS-derived cells can be tested in an animal model, the difficulty in demonstrating therapeutic application of these FA-human iPS cells hemotopoeitic progenitors in an in vivo model remains a challenge.

\section{CONCLUDING REMARKS}

Many challenges lie ahead before iPS cells can be brought into the clinic. Nonetheless, the research community has learned much about the properties of these cells in a relatively short period of time. Interestingly, several studies have shown that differentiated cells can be directly transdifferen-tiated into neurons and insulin-producing cells, obviating the need for reprogramming [71, 72]. Nevertheless, the question remains: are ES cells and iPS cells equivalent and can they be employed in the same manner? From the studies carried out so far, the answer may be a reserved yes. It is worthy to note that, in more than one case, marked differences have been observed between differentiated progenies from iPS and ES cells [29, 40, 44, 56, 62, 63]. However, dissimi-larities in the differentiation potential across ES cell lines have also been reported [73, 74]. Therefore the question of whether these differences are attributed to within or across cell types awaits the establishment of more systematic and standard approaches to iPS cell characterization before it can be solved.

\section{ACKNOWLEDGEMENT}

We thank Dr. Jeremy Crook for critically reviewing this manuscript.

\section{REFERENCES}

[1] Takahashi K, Yamanaka S. Induction of pluripotent stem cells from mouse embryonic and adult fibroblast cultures by defined factors. Cell 2006; 126(4): 663-76.

[2] Yu J, Vodyanik MA, Smuga-Otto K, et al. Induced pluripotent stem cell lines derived from human somatic cells. Science 2007; 318(5858): 1917-20.

[3] Takahashi K, Tanabe K, Ohnuki M, et al. Induction of pluripotent stem cells from adult human fibroblasts by defined factors. Cell 2007; 131(5): 861-72.

[4] Reubinoff BE, Pera MF, Fong CY, et al. Embryonic stem cell lines from human blastocysts: somatic differentiation in vitro. Nat Biotechnol 2000; 18(4): 399-404.

[5] Thomson JA, Itskovitz-Eldor J, Shapiro SS, et al. Embryonic stem cell lines derived from human blastocysts. Science 1998; 282(5391): 1145-7.

[6] Park IH, Arora N, Huo H, et al. Disease-specific induced pluripotent stem cells. Cell 2008; 134(5): 877-86.

[7] Choo AB, Tan HL, Ang SN, et al. Selection against undifferentiated human embryonic stem cells by a cytotoxic antibody recognizing podocalyxin-like protein-1. Stem Cells. 2008; 26(6): 1454-63.

[8] Tan HL, Fong WJ, Lee EH, et al. mAb 84, a cytotoxic antibody that kills undifferentiated human embryonic stem cells via oncosis. Stem Cells 2009; 27(8): 1792-801.

[9] Aasen T, Raya A, Barrero MJ, et al. Efficient and rapid generation of induced pluripotent stem cells from human keratinocytes. Nat Biotechnol 2008; 26(11): 1276-84.

[10] Yamanaka S. A fresh look at iPS cells. Cell 2009; 137(1): 13-7.

[11] Masaki H, Ishikawa $\mathrm{T}$, Takahashi S, et al. Heterogeneity of pluripotent marker gene expression in colonies generated in human iPS cell induction culture. Stem Cell Res 2007; 1(2): 105-15.

[12] Watanabe K, Ueno M, Kamiya D, et al. A ROCK inhibitor permits survival of dissociated human embryonic stem cells. Nat Biotechnol 2007; 25(6): 681-6. 
[13] Huangfu D, Osafune K, Maehr R, et al. Induction of pluripotent stem cells from primary human fibroblasts with only Oct4 and Sox2. Nat Biotechnol 2008; 26(11): 1269-75.

[14] Marion RM, Strati K, Li H, et al. Telomeres acquire embryonic stem cell characteristics in induced pluripotent stem cells. Cell Stem Cell 2009; 4(2): 141-54.

[15] Maherali N, Sridharan R, Xie W, et al. Directly reprogrammed fibroblasts show global epigenetic remodeling and widespread tissue contribution. Cell Stem Cell 2007; 1(1): 55-70.

[16] Nakagawa M, Koyanagi M, Tanabe K, et al. Generation of induced pluripotent stem cells without Myc from mouse and human fibroblasts. Nat Biotechnol 2008; 26(1): 101-6.

[17] Park IH, Zhao R, West JA, et al. Reprogramming of human somatic cells to pluripotency with defined factors. Nature 2008; 451(7175): 141-6.

[18] Adewumi O, Aflatoonian B, Ahrlund-Richter L, et al. Characterization of human embryonic stem cell lines by the International Stem Cell Initiative. Nat Biotechnol 2007; 25(7): 80316.

[19] Chin MH, Mason MJ, Xie W, et al. Induced pluripotent stem cells and embryonic stem cells are distinguished by gene expression signatures. Cell Stem Cell 2009; 5(1): 111-23.

[20] Lowry WE, Richter L, Yachechko R, et al. Generation of human induced pluripotent stem cells from dermal fibroblasts. Proc Natl Acad Sci USA 2008; 105(8): 2883-8.

[21] Ellis J, Bruneau BG, Keller G, et al. Alternative induced pluripotent stem cell characterization criteria for in vitro applications. Cell Stem Cell 2009; 4(3): 198-9.

[22] Rubin LL. Stem cells and drug discovery: the beginning of a new era? Cell 2008; 132(4): 549-52.

[23] Erceg S, Ronaghi M, Stojkovic M. Human embryonic stem cell differentiation toward regional specific neural precursors. Stem Cells 2009; 27(1): 78-87.

[24] Dhara SK, Stice SL. Neural differentiation of human embryonic stem cells. J Cell Biochem 2008; 105(3): 633-40.

[25] Crook JM, Kobayashi NR. Human stem cells for modeling neurological disorders: accelerating the drug discovery pipeline. J Cell Biochem 2008; 105(6): 1361-6.

[26] Phillips BW, Crook JM. Pluripotent human stem cells: a novel tool in drug discovery. BioDrugs 2010; 24(2): 99-108

[27] Karumbayaram S, Novitch BG, Patterson M, et al. Directed differentiation of human-induced pluripotent stem cells generates active motor neurons. Stem Cells. 2009; 27(4): 806-11.

[28] Chambers SM, Fasano CA, Papapetrou EP, et al. Highly efficient neural conversion of human ES and iPS cells by dual inhibition of SMAD signaling. Nat Biotechnol 2009; 27(3): 275-80.

[29] Hu BY, Weick JP, Yu J, et al. Neural differentiation of human induced pluripotent stem cells follows developmental principles but with variable potency. Proc Natl Acad Sci USA 2010; 107(9): 4335-40.

[30] Dimos JT, Rodolfa KT, Niakan KK, et al. Induced pluripotent stem cells generated from patients with ALS can be differentiated into motor neurons. Science 2008; 321(5893): 1218-21.

[31] Ebert AD, Yu J, Rose FF Jr, et al. Induced pluripotent stem cells from a spinal muscular atrophy patient. Nature 2009; 457(7227): 277-80.

[32] Lee G, Papapetrou EP, Kim H, et al. Modelling pathogenesis and treatment of familial dysautonomia using patient-specific iPSCs. Nature 2009; 461(7262): 402-6.

[33] Soldner F, Hockemeyer D, Beard C, et al. Parkinson's disease patient-derived induced pluripotent stem cells free of viral reprogramming factors. Cell 2009; 136(5): 964-77.

[34] Cai J, Yang M, Poremsky E, et al. Dopaminergic neurons derived from human induced pluripotent stem cells survive and integrate into 6-ohda lesioned rats. Stem Cells Dev 2010; 19: 1017-23.

[35] Wernig M, Zhao JP, Pruszak J, et al. Neurons derived from reprogrammed fibroblasts functionally integrate into the fetal brain and improve symptoms of rats with Parkinson's disease. Proc Natl Acad Sci USA 2008; 105(15): 5856-61.

[36] Thygesen K, Alpert JS, White HD, et al. Universal definition of myocardial infarction. Circulation 2007; 116(22): 2634-53.

[37] Ahuja P, Sdek P, MacLellan WR. Cardiac myocyte cell cycle control in development, disease, and regeneration. Physiol Rev 2007; 87(2): 521-44.
[38] Narazaki G, Uosaki H, Teranishi M, et al. Directed and systematic differentiation of cardiovascular cells from mouse induced pluripotent stem cells. Circulation 2008; 118(5): 498-506.

[39] Schenke-Layland K, Rhodes KE, Angelis E, et al. Reprogrammed mouse fibroblasts differentiate into cells of the cardiovascular and hematopoietic lineages. Stem Cells 2008; 26(6): 1537-46.

[40] Mauritz C, Schwanke K, Reppel M, et al. Generation of functional murine cardiac myocytes from induced pluripotent stem cells. Circulation 2008; 118(5): 507-17.

[41] Zhang J, Wilson GF, Soerens AG, et al. Functional cardiomyocytes derived from human induced pluripotent stem cells. Circ Res 2009; 104(4): e30-41.

[42] Zwi L, Caspi O, Arbel G, et al. Cardiomyocyte differentiation of human induced pluripotent stem cells. Circulation 2009; 120(15): 1513-23.

[43] Xu Q. Stem cells and transplant arteriosclerosis. Circ Res 2008; 102(9): 1011-24

[44] Xie CQ, Huang H, Wei S, et al. A comparison of murine smooth muscle cells generated from embryonic versus induced pluripotent stem cells. Stem Cells Dev 2009; 18(5): 741-8.

[45] Lee TH, Song SH, Kim KL, et al. Functional recapitulation of smooth muscle cells via induced pluripotent stem cells from human aortic smooth muscle cells. Circ Res 2009; 106(1): 120-8

[46] Lian Q, Zhang Y, Zhang J, et al. Functional mesenchymal stem cells derived from human induced pluripotent stem cells attenuate limb ischemia in mice. Circulation 2010; 121(9): 1113-23.

[47] White SA, Shaw JA, Sutherland DE. Pancreas transplantation. Lancet 2009; 373(9677): 1808-17.

[48] Tateishi K, He J, Taranova O, et al. Generation of insulin-secreting islet-like clusters from human skin fibroblasts. J Biol Chem 2008; 283(46): 31601-7

[49] Zhang D, Jiang W, Liu M, et al. Highly efficient differentiation of human ES cells and iPS cells into mature pancreatic insulinproducing cells. Cell Res 2009; 19(4): 429-38.

[50] Kung JW, Forbes SJ. Stem cells and liver repair. Curr Opin Biotechnol 2009; 20(5): 568-74.

[51] Ogawa S, Miyagawa S. Potentials of regenerative medicine for liver disease. Surg Today 2009; 39(12): 1019-25.

[52] Gai H, Nguyen DM, Joon Moon Y, et al. Generation of murine hepatic lineage cells from induced pluripotent stem cells. Differentiation 2010; 79(3): 171-81.

[53] Li W, Wang D, Qin J, et al. Generation of functional hepatocytes from mouse induced pluripotent stem cells. J Cell Physiol 2010; 222(3): 492-501.

[54] Choi KD, Vodyanik MA, Slukvin, II. Generation of mature human myelomonocytic cells through expansion and differentiation of pluripotent stem cell-derived lin-CD34+CD43+CD45+ progenitors. J Clin Invest 2009; 119(9): 2818-29.

[55] Choi KD, Yu J, Smuga-Otto K, et al. Hematopoietic and endothelial differentiation of human induced pluripotent stem cells. Stem Cells 2009; 27(3): 559-67.

[56] Feng Q, Lu SJ, Klimanskaya I, et al. Hemangioblastic derivatives from human induced pluripotent stem cells exhibit limited expansion and early senescence. Stem Cells 2010; 28: 704-12.

[57] Senju S, Haruta M, Matsunaga Y, et al. Characterization of dendritic cells and macrophages generated by directed differentiation from mouse induced pluripotent stem cells. Stem Cells 2009; 27(5): 1021-31.

[58] Ye Z, Zhan H, Mali P, et al. Human-induced pluripotent stem cells from blood cells of healthy donors and patients with acquired blood disorders. Blood 2009; 114(27): 5473-80.

[59] Kaufman RJ. Advances toward gene therapy for hemophilia at the millennium. Hum Gene Ther 1999; 10(13): 2091-107.

[60] Xu D, Alipio Z, Fink LM, et al. Phenotypic correction of murine hemophilia A using an iPS cell-based therapy. Proc Natl Acad Sci USA 2009; 106(3): 808-13.

[61] Buchholz DE, Hikita ST, Rowland TJ, et al. Derivation of functional retinal pigmented epithelium from induced pluripotent stem cells. Stem Cells 2009; 27(10): 2427-34.

[62] Hirami Y, Osakada F, Takahashi K, et al. Generation of retinal cells from mouse and human induced pluripotent stem cells. Neurosci Lett 2009; 458(3): 126-31.

[63] Osakada F, Jin ZB, Hirami Y, et al. In vitro differentiation of retinal cells from human pluripotent stem cells by small-molecule induction. J Cell Sci 2009; 122(Pt 17): 3169-79. 
[64] Parameswaran S, Balasubramanian S, Babai N, et al. Induced pluripotent stem cells (iPSCs) generate both retinal ganglion cells and photoreceptors: therapeutic implications in degenerative changes in glaucoma and age-related macular degeneration. Stem Cells 2010; 28: 695-703.

[65] Meyer JS, Shearer RL, Capowski EE, et al. Modeling early retinal development with human embryonic and induced pluripotent stem cells. Proc Natl Acad Sci USA 2009; 106(39): 16698-703.

[66] Hegele RA, Joy TR, Al-Attar SA, et al. Thematic review series: Adipocyte Biology. Lipodystrophies: windows on adipose biology and metabolism. J Lipid Res 2007; 48(7): 1433-44.

[67] Arner P. Resistin: yet another adipokine tells us that men are not mice. Diabetologia 2005; 48(11): 2203-5.

[68] Taura D, Noguchi M, Sone M, et al. Adipogenic differentiation of human induced pluripotent stem cells: comparison with that of human embryonic stem cells. FEBS Lett 2009; 583(6): 1029-33.

[69] Hanna J, Wernig M, Markoulaki S, et al. Treatment of sickle cell anemia mouse model with iPS cells generated from autologous skin. Science 2007; 318(5858): 1920-3.
[70] Raya A, Rodriguez-Piza I, Guenechea G, et al. Disease-corrected haematopoietic progenitors from Fanconi anaemia induced pluripotent stem cells. Nature 2009; 460: 53-9.

[71] Murtaugh LC, Melton DA. Genes, signals, and lineages in pancreas development. Annu Rev Cell Dev Biol 2003; 19: 71-89.

[72] Vierbuchen T, Ostermeier A, Pang ZP, et al. Direct conversion of fibroblasts to functional neurons by defined factors. Nature 463(7284): 1035-41.

[73] Osafune K, Caron L, Borowiak M, et al. Marked differences in differentiation propensity among human embryonic stem cell lines. Nat Biotechnol 2008; 26(3): 313-5.

[74] $\mathrm{Wu} \mathrm{H}, \mathrm{Xu} \mathrm{J}$, Pang ZP, et al. Integrative genomic and functional analyses reveal neuronal subtype differentiation bias in human embryonic stem cell lines. Proc Natl Acad Sci USA 2007; 104(34): 13821-6.

[75] Heins N, Lindahl A, Karlsson U, et al. Clonal derivation and characterization of human embryonic stem cell lines. J Biotechnol 2006; 122(4): 511-20.

[76] Taura D, Sone M, Homma K, et al. Induction and isolation of vascular cells from human induced pluripotent stem cells--brief report. Arterioscler Thromb Vasc Biol 2009; 29(7): 1100-103.

(C) Ng and Choo; Licensee Bentham Open.

This is an open access article licensed under the terms of the Creative Commons Attribution Non-Commercial License (http://creativecommons.org/licenses/by$\mathrm{nc} / 3.0 /$ ), which permits unrestricted, non-commercial use, distribution and reproduction in any medium, provided the work is properly cited. 